\title{
Monoglyceride surfactants from arginine: synthesis and biological properties
}

\author{
Lourdes Pérez,* Aurora Pinazo, Maria Teresa García, Maria del Carmen Morán \\ and Maria Rosa Infante
}

Departamento de Tecnología de Tensioactivos, Instituto de Investigaciones Quimicas y
Ambientales de Barcelona, CSIC, Jordi Girona 18-26, 08034 Barcelona, Spain.
E-mail: Ipmste@ cid.csic.es; Fax: + 34 32045904; Tel: + 34934006164

Received (in Toulouse, France) 16th April 2004, Accepted 20th July 2004

First published as an Advance Article on the web 19th October 2004

\begin{abstract}
A novel family of dicationic arginine-monoglyceride surfactants, 1-acyl-3- $O$-(L-arginyl)-rac-glycerol $\cdot 2 \mathrm{HCl}$, was synthesised and characterised. They have one alkyl chain of with length in the range of $\mathrm{C}_{10}-\mathrm{C}_{14}$ attached to the glycerol though esters bonds and a dicationic polar head from the arginine. Structurally they can be regarded as analogues of the monoglycerides, widely used as emulsifiers in the food and in the pharmaceutical industry. The introduction of the basic amino acid arginine into the monoglycerides increases the solubility of these compounds and improves their antimicrobial activity. Moreover, the acute toxicity of these surfactants against Daphnia magna is clearly lower than the toxicity reported for conventional cationic surfactants.
\end{abstract}

\section{Introduction}

At present the main driving force behind the development of novel surfactants and emulsifiers is the search for environmentally friendly products. Mono-diglycerides and amino acid based surfactants are biocompatible compounds used in the cosmetic and food industries. Mono-diglycerides is a common term describing a mixture of mono- and diglycerides, which are produced by glycerolyses of fats or by esterification of glycerol with fatty acids. Owing to their amphiphilic properties, these compounds are widely used as emulsifiers in the food industry, for example, in margarine, low-calorie spreads, dairy products and dressings. ${ }^{1}$ The emulsification properties of these molecules are also used in pharmaceutical and cosmetic applications. Moreover, food formulations in terms of calories, fat content, vitamins or minerals change all the time because of new insights into eating patterns and health aspects. ${ }^{2}$ This leads to a constant demand for the optimisation of product formulations, including optimal selection of raw materials. Thus, information on different glycerides, especially monoglyceride derivatives, is of great interest to the industry.

In the last two decades, our group has published a number of papers addressing the synthesis of biocompatible amino acid based surfactants. ${ }^{3-7}$ In this regard, we have reported a novel family of natural cationic surfactants, 1,2-diacyl-3- $O$-(L-arginyl)-rac-glycerols, structural analogues of partial glycerides and phospholipids with the amino acid arginine in the polar head. ${ }^{8}$ These diglyceride surfactants show a self-aggregation behaviour comparable to that of short-chain lecithins. ${ }^{9}$ Moreover, they show a low toxicity profile and an antimicrobial activity similar to those of conventional cationic surfactants.

In this paper, we describe a novel family of dicationic arginine based surfactants, 1-acyl-3-O-(L-arginyl)-rac-glycerol . $2 \mathrm{HCl}$ (X0R; Fig. 1) with alkyl chain lengths in the range of $\mathrm{C}_{10}-\mathrm{C}_{14}$. These surfactants have a hydrophobic chain attached to the glycerol backbone through ester bonds and a cationic polar head from the arginine amino acid. Structurally they can be regarded as analogues of the monoglycerides, but they possess a cationic character because of the presence of arginine. The aim of this work is to obtain compounds with physical properties similar to those of the monoglycerides and with improved antimicrobial properties due to the basic amino acid arginine.

We report the chemical synthesis and the study of some physical properties such as the critical micellar concentration. Biological properties such as antimicrobial activity and aquatic toxicity are also investigated.

\section{Experimental}

\section{Materials}

All solvents were reagent grade and were used without further purification. Anhydrous glycerol and the acyl chlorides with 12 and 14 carbon atoms were from Fluka and pure 1-decylglycerol (denoted 10,0,0) from Sigma.

The progress of the reactions was monitored by HPLC, model Merck-Hitachi D-2500, using a UV-Vis detector L4250 at $215 \mathrm{~nm}$. A Lichrospher $100 \mathrm{CN}$ (propylcyano), $5 \mu \mathrm{m}$, $250 \times 4 \mathrm{~mm}$ column was used. A gradient elution profile was employed from the initial solvent composition of A-B $(75: 25$ by volume), changing over $24 \mathrm{~min}$ to a final composition of 5:95 where solvent $\mathrm{A}$ is $0.1 \%(\mathrm{vol} / \mathrm{vol})$ trifluoroacetic acid (TFA) in $\mathrm{H}_{2} \mathrm{O}$ and solvent $\mathrm{B}$ is $0.085 \%$ of TFA in $\mathrm{H}_{2} \mathrm{O}-\mathrm{CH}_{3} \mathrm{CN}$ $(1: 4)$. The flow rate through the column was $1.0 \mathrm{ml} \mathrm{min}^{-1}$.

\section{Methods}

The structures of the pure compounds were checked by ${ }^{1} \mathrm{H}$ and ${ }^{13} \mathrm{C}$ nuclear magnetic resonance (NMR) analyses, which were recorded on a Varian spectrometer at $499.803\left({ }^{1} \mathrm{H}\right)$ and 125.233 $\left({ }^{13} \mathrm{C}\right) \mathrm{MHz}$, respectively, using the deuterium signal of the solvent as the lock. Chemical shifts $(\delta)$ are reported in parts per million (ppm) downfield from tetramethylsilane (TMS). All measurements were carried out on $0.6 \mathrm{ml}$ samples in $5 \mathrm{~mm}$ tubes using a $5 \mathrm{~mm}$ indirect broadband probe. ${ }^{13} \mathrm{C}$ NMR spectra were recorded under composite decoupling to eliminate ${ }^{13} \mathrm{C}-{ }^{1} \mathrm{H}$ coupling. The distortionless enhancement by polarisation transfer ${ }^{10}$ spectra (DEPT) were run in a standard way to separate the $\mathrm{CH} / \mathrm{CH}_{3}$ and $\mathrm{CH}_{2}$ lines phased up and down, respectively. The 2D-PFG HSQC (pulsed field gradient 


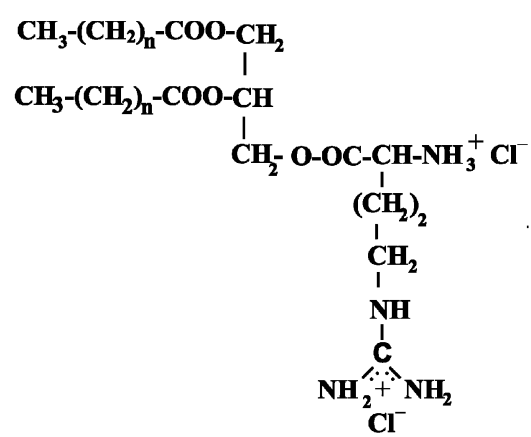

1) 1,2- diacyl-3-O-(L-arginyl)rac-glycerol -2(HCl) XXR
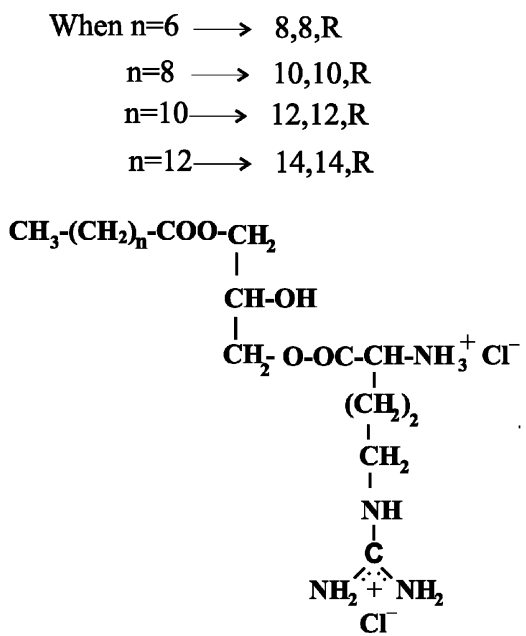

2) 1- acyl-3-O-(L-arginyl)rac-glycerol- 2(HCl) XOR

$$
\begin{aligned}
& \text { When } \mathrm{n}=8 \longrightarrow 10,0, \mathrm{R} \\
& \mathrm{n}=10 \longrightarrow 12,0, \mathrm{R} \\
& \mathrm{n}=12 \longrightarrow 14,0, \mathrm{R}
\end{aligned}
$$

Fig. 1 Molecular structure of the (a) 1,2-diacyl-3-O-(L-arginyl)-racglycerol $2 \mathrm{HCl}(\mathrm{XXR})$ and (b) 1-acyl-3-O-(L-arginyl)-rac-glycerol $2 \mathrm{HCl}(\mathrm{X} 0 \mathrm{R})$.

heteronuclear single quantum correlation) and 2D-PFG $\mathrm{HMBC}^{11}$ (pulsed field gradient heteronuclear multiple bond correlation) were obtained using the standard Varian pulse programs.

Mass spectroscopy (MS) with fast atom bombardment (FAB) or electrospray techniques was carried out with a VGQUATTRO from Fisons Instruments. Elemental analysis of the final compounds was also achieved.

Samples for conductivity measurements were prepared by weight in Millipore ultra pure water. Conductivity was measured at $25{ }^{\circ} \mathrm{C}$ using a Crisson 525 with platinised parallel plates with a constant of $0.998 \mathrm{~cm}^{-1}$ and working at $1 \mathrm{KHz}$. The cell constant was calibrated periodically with standard sodium chloride solutions. Measurements were made at increasing concentrations to minimise errors from possible electrode contamination.

A Krüss KA12 tensiometer with a roughened platinum plate attached to a precision torsion balance was used to measure equilibrium surface tensions.

\section{Syntheses}

1-Acyl-3-O-( $\mathrm{N}$-Cbz-L-arginyl)-rac-glycerols (X0RZ). The X0RZ were prepared from $N$-Cbz-L-arginyl-rac-glycerol (00RZ) synthesised in our laboratory following the method described in ref. 8. A solution of pyridine or acetonitrile (saturated with sodium bicarbonate) containing $0.015 \mathrm{~mol}$ $(5 \mathrm{~g})$ of $00 \mathrm{RZ}$ was placed in a round-bottomed flask. To this solution $0.03 \mathrm{~mol}$ of the corresponding acyl chloride was added dropwise and stirring continued at room temperature for $4 \mathrm{~h}$. After completion of the reaction, pyridine was removed by vacuum pump. The resulting solid was dissolved in methanol and extracted three times with petroleum ether to remove the corresponding fatty acid excess. The solvent was evaporated and the solid was redissolved in chloroform. This solution was shaken with water to eliminate water-soluble impurities.

Silica acid flash chromatography: $100 \mathrm{ml}$ of silica (Chromagel 60A CC, 70-230) was packed into a flash chromatography column. Then $3 \mathrm{~g}$ of X0RZ dissolved in chloroform was loaded into the column and eluted from chloroform to chloroformmethanol. The fractions containing the desired products were pooled. The identification of the products was carried out by HPLC, elemental analysis, ${ }^{1} \mathrm{H}$ NMR and ${ }^{13} \mathrm{C}$ NMR. The assignments in ${ }^{1} \mathrm{H}$ NMR and ${ }^{13} \mathrm{C}$ NMR correspond to the molecules in Fig. 2.

1-Decyl-3-O-(N-Cbz-L-arginyl)-rac-glycerol (as hydrochloride salt). Yield $60 \%$. HPLC $t_{\mathrm{r}}=15.1 \mathrm{~min} ; \mathrm{MW} 572.5$; anal. found: C, 55.0; H, 8.0; N, 9.4; Cl, 6.4; calcd for $\mathrm{C}_{27} \mathrm{H}_{45} \mathrm{O}_{7}$ $\mathrm{N}_{4} \mathrm{Cl} \cdot \mathrm{H}_{2} \mathrm{O}, \mathrm{C}, 54.9 ; \mathrm{H}, 8.0 ; \mathrm{N}, 9.5 ; \mathrm{Cl}, 6.0 .{ }^{1} \mathrm{H}$ NMR $\left(\mathrm{CD}_{3} \mathrm{OD}\right)$ : $\delta_{\mathrm{H}} 0.89\left[\mathrm{t}, 3 \mathrm{H},\left(\mathrm{CH}_{3}\right.\right.$ of the alkyl chain)], $1.29\left[\mathrm{~s}, 14 \mathrm{H},\left(7 \mathrm{CH}_{2}\right.\right.$ of the alkyl chain), $1.50-1.96\left[\mathrm{~m}, 6 \mathrm{H},\left(-\mathrm{CH}_{2}-\mathrm{CH}_{2}-\mathrm{CH}_{2}-\mathrm{COO}-\right)\right.$, (9)], $2.35\left[\mathrm{t},\left(-\mathrm{CH}_{2}-\mathrm{COO}-\right)\right], 3.20[\mathrm{~m},(10)], 4.0-4.3[\mathrm{~m}, 6 \mathrm{H},(1)$, (2), (3), (5)], 5.09 [s, 2H, (8)], 7.22-7.37 [m, 5H, (15), (16), (17), (18), (19)], ${ }^{13} \mathrm{C}$ NMR $\left(\mathrm{CD}_{3} \mathrm{OD}\right): \delta_{\mathrm{C}} 14.45\left[\mathrm{CH}_{3}-\right.$, alkyl chain], 23.72-41.87 [- $\mathrm{CH}_{2}-$ alkyl chain and (9), (10)], 55.04 [(5)], 65.89 $[(1)], 66.74[(3)], 67.78[(8)], 68.28[(2)], 128.84[(19)], 129.06$ $[(17)$ and (18)], $129.49[(15)$ and (16)], $138.09[(14)], 158.59$ [(12)], $158.62[(7)], 173.34[(4)], 175.26[(20)]$.

1-Dodecyl-3-O-( $\mathrm{N}$-Cbz-L-arginyl)-rac-glycerol (as hydrochloride salt). Yield 68\%. HPLC $t_{\mathrm{r}}=17.3 \mathrm{~min}$; MW 600.5; anal. found: $\mathrm{C}, 57.3 ; \mathrm{H}, 8.6 ; \mathrm{N}, 8.9 ; \mathrm{Cl}, 6.1$; calcd for $\mathrm{C}_{29} \mathrm{H}_{49} \mathrm{O}_{7} \mathrm{~N}_{4} \mathrm{Cl} \cdot 1 / 2 \mathrm{H}_{2} \mathrm{O}, \mathrm{C}, 57.0 ; \mathrm{H}, 8.20 ; \mathrm{N}, 9.18 ; \mathrm{Cl}, 5.82$. ${ }^{1} \mathrm{H}$ NMR $\left(\mathrm{CD}_{3} \mathrm{OD}\right): \delta_{\mathrm{H}} 0.88$ [t, $3 \mathrm{H},\left(\mathrm{CH}_{3}\right.$ of the alkyl chain)], $1.30\left[\mathrm{~s}, 18 \mathrm{H}, 9 \mathrm{CH}_{2}\right.$ of the alkyl chain) $], 1.51-2.00[\mathrm{~m}, 6 \mathrm{H}$, $\left.\left(-\mathrm{CH}_{2}-\mathrm{CH}_{2}-\mathrm{COO}-\right),(9)\right], 2.38$ [t, $\left.\left(-\mathrm{CH}_{2}-\mathrm{COO}-\right)\right], 3.19$ [m, (10)], 4.01-4.22 [m, 6H, (1). (2), (3), (5)], 5.09 [s, 2H, (8)], 7.22-7.37 [m, 5H, (15), (16), (17), (18), (19)], ${ }^{13} \mathrm{C}$ NMR $\left(\mathrm{CD}_{3} \mathrm{OD}\right)$ : $\delta_{\mathrm{C}} 14.47\left[\mathrm{CH}_{3}-\right.$, alkyl chain], 23.75-41.83 $\left[-\mathrm{CH}_{2}-\right.$ alkyl chain and (9), (10)], $55.07[(5)], 65.91[(1)], 66.77[(3)], 67.79[(8)]$, $68.21[(2)], 128.84[(19)], 129.06[(17)$ and $(18)], 129.48[(15)$ and $(16)], 138.11[(14)], 158.54[(12)], 158.66[(7)], 173.36[(4)]$, $175.26[(20)]$.

1-Mirystoyl-3-O-(N-Cbz-L-arginyl)-rac-glycerol (as hydrochloride salt). Yield 71\%. HPLC $t_{\mathrm{r}}=19.9 \mathrm{~min}$; MW 628.5; anal. found: $\mathrm{C}, 58.90 ; \mathrm{H}, 8.5 ; \mathrm{N}, 8.73 ; \mathrm{Cl}, 5.67$; calcd for $\mathrm{C}_{31} \mathrm{H}_{53} \mathrm{O}_{7} \mathrm{~N}_{4} \mathrm{Cl} \cdot \mathrm{H}_{2} \mathrm{O}, \mathrm{C}, 59.18 ; \mathrm{H}, 8.43 ; \mathrm{N}, 8.91 ; \mathrm{Cl}, 5.64$. MS: $m / z$ 635.1. ${ }^{1} \mathrm{H}$ NMR $\left(\mathrm{CD}_{3} \mathrm{OD}\right): \delta_{\mathrm{H}} 0.90\left[\mathrm{t}, 3 \mathrm{H},\left(\mathrm{CH}_{3}\right.\right.$ of the alkyl chain) ], $1.35\left[\mathrm{~s}, 22 \mathrm{H}, 11 \mathrm{CH}_{2}\right.$ of the alkyl chain)], 1.502.07 [m, 6H, (- $\left.\left.\mathrm{CH}_{2}-\mathrm{CH}_{2}-\mathrm{COO}-\right),(9)\right], 2.30$ [t, (- $\left.\mathrm{CH}_{2}-\mathrm{COO}-\right)$ ], $3.20[\mathrm{~m},(10)], 4.07-4.21[\mathrm{~m}, 6 \mathrm{H},(2),(3),(5)], 5.03$ [s, 2H, (8)], 7.22-7.33 [m, 5H, (15), (16), (17), (18), (19)], ${ }^{13} \mathrm{C}$ NMR $\left(\mathrm{CD}_{3} \mathrm{OD}\right): \delta_{\mathrm{C}} 14.46\left[\mathrm{CH}_{3}-\right.$, alkyl chain $], 23.74-41.85\left[-\mathrm{CH}_{2}-\right.$ alkyl chain and (9), (10)], 55.07 [(5)], 65.89 [(1)], 66.69 [(3)], $67.78[(8)], 68.27[(2)], 128.85[(19)], 129.05[(17)$ and $(18)]$, $129.49[(15)$ and $(16)], 138.09[(14)], 158.58[(12)], 158.66[(7)]$, $173.38[(4)], 175.27[(20)]$.

1-Acyl-3- $\boldsymbol{O}$-(L-arginyl)-rac-glycerol (X0R). The X0R compounds were obtained by hydrogenation of the corresponding pure $\mathrm{X} 0 \mathrm{RZ}(0.002 \mathrm{~mol})$ in $30 \mathrm{ml}$ methanol using $\mathrm{Pd}$ in activated charcoal $(10 \% \mathrm{Pd})$ as catalyst. The mixture was stirred for $30 \mathrm{~min}$. At the end of the reaction, the catalyst 


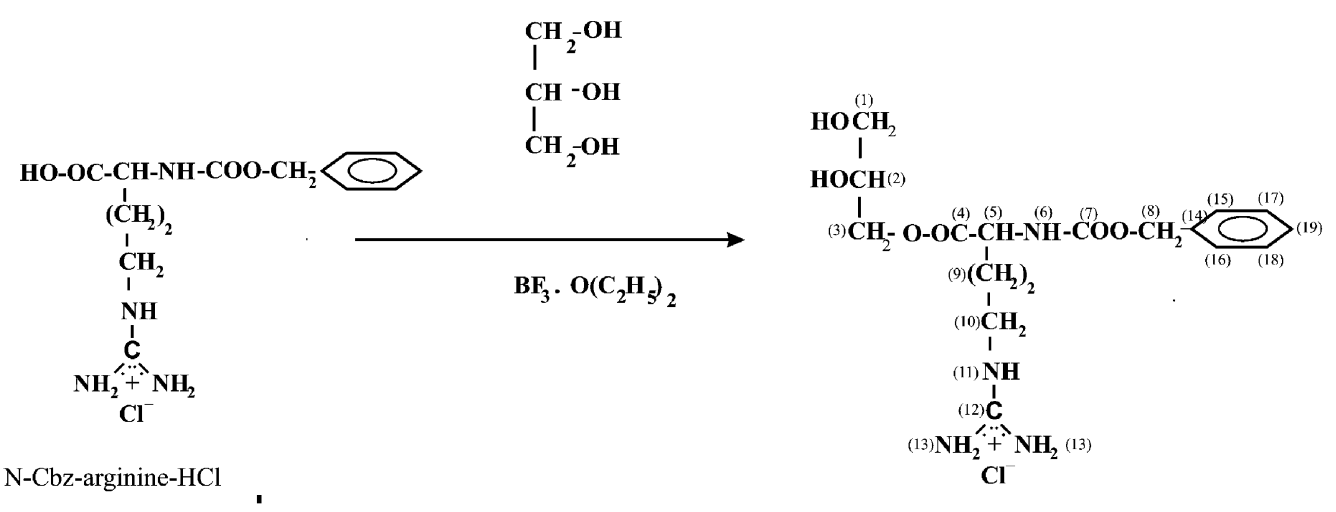

1-O-(N-Cbz-L-arginyl)rac-glycerol-HCl OORZ

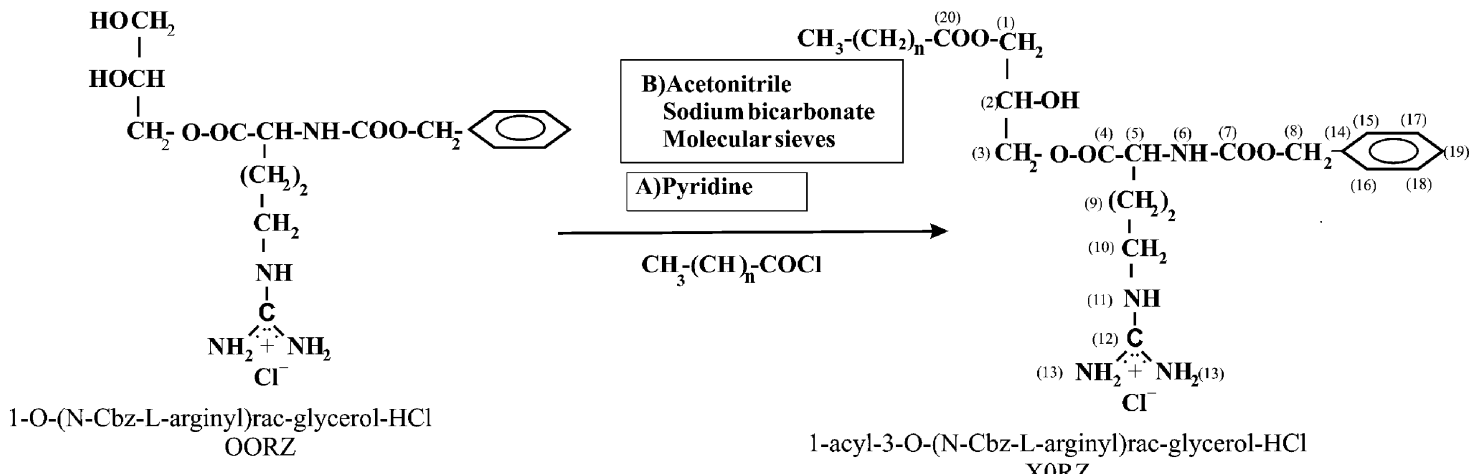

$\mathrm{X} 0 \mathrm{RZ}$

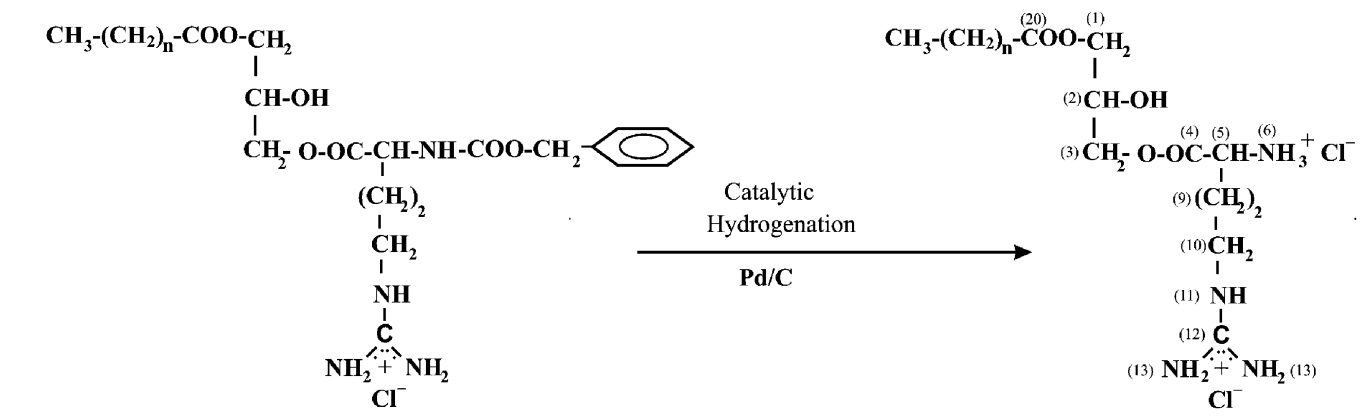

1-acyl-3-O-(N-Cbz-L-arginyl)rac-glycerol-HCl XORZ

1-acyl-3-O-(L-arginyl)rac-glycerol-2(HCl)

$\mathrm{XOR}$

Fig. 2 Synthetic pathway for the preparation of the 1 acyl-3-O-(L-arginyl)-rac-glycerol $\cdot 2 \mathrm{HCl}$ surfactants.

was filtered off on celite. The solvent was evaporated under reduced pressure. Pure compounds were obtained by several crystallisations from methanol-acetone. Analytical data and spectral assignments for the X0R surfactants are shown in Tables 1 and 2 .

\section{Antimicrobial activity}

The compounds tested were dissolved in nutrient agar medium in the concentration range of $0.1-256 \mu \mathrm{g} \mathrm{ml}^{-1}$. Then $10 \mu \mathrm{l}$ of a nutrient broth starter culture of the each bacterial strain was added to achieve a final inoculum of $c a .5 \times 10^{-4}$ to $5 \times 10^{-5}$ colony forming units per $\mathrm{ml}$. The cultures were incubated overnight at $37{ }^{\circ} \mathrm{C}$. Nutrient broth medium without the compound served as control. Growth of the microorganisms was determined visually after incubation for $24 \mathrm{~h}$ at $37^{\circ} \mathrm{C}$. The development of turbidity in an inoculated medium is a function of growth. A rise in turbidity reflects increases in both mass and cell number. Changes in turbidity were correlated with changes in cell numbers. The lowest concentration of antimicrobial agent at which no visible turbidity was observed was taken as the minimum inhibitory concentration.

\section{Aquatic toxicity tests}

To determine aquatic toxicity, Daphnia magna acute toxicity tests $^{12}$ were carried out. Daphnia magna, laboratory bred, not more than $24 \mathrm{~h}$ old, were used in this test, where swimming incapacity is the end point. The $\mathrm{pH}$ of the medium was 8.0 and the total hardness was $250 \mathrm{mg} \mathrm{L}^{-1}\left(\right.$ as $\left.\mathrm{CaCO}_{3}\right)$, with a $\mathrm{Ca}: \mathrm{Mg}$ ratio of $4: 1$. Tests were performed in the dark at $20^{\circ} \mathrm{C}$. Twenty Daphnia, divided into four groups of five animals each, were 
Table 1 Analytical data of the 1-acyl-3-O-(L-arginyl)-rac-glycerols (X0R)

\begin{tabular}{|c|c|c|c|c|c|c|}
\hline \multirow[b]{2}{*}{ Compound } & \multirow[b]{2}{*}{ Molecular formula (molecular weight) } & \multirow[b]{2}{*}{ HPLC retention time $/ \mathrm{min}$} & \multicolumn{4}{|c|}{ Elemental analysis calcd ${ }^{a}$ (found) } \\
\hline & & & $\% \mathrm{C}$ & $\% \mathrm{H}$ & $\% \mathrm{~N}$ & $\% \mathrm{Cl}$ \\
\hline $100 \mathrm{R}$ & $\mathrm{C}_{19} \mathrm{H}_{40} \mathrm{~N}_{4} \mathrm{O}_{5} \mathrm{Cl}_{2}(475)$ & 16.0 & $42.4(42.2)$ & $8.7(8.5)$ & $10.4(10.3)$ & $13.2(13.6)$ \\
\hline $120 \mathrm{R}$ & $\mathrm{C}_{21} \mathrm{H}_{44} \mathrm{~N}_{4} \mathrm{O}_{5} \mathrm{Cl}_{2}(503)$ & 17.0 & $46.8(46.5)$ & $8.9(8.8)$ & $10.4(10.5)$ & $13.3(13.7)$ \\
\hline $140 \mathrm{R}$ & $\mathrm{C}_{23} \mathrm{H}_{48} \mathrm{~N}_{4} \mathrm{O}_{5} \mathrm{Cl}_{2}(531)$ & 19.3 & $47.9(47.9)$ & $9.2(9.5)$ & $9.7(9.6)$ & $12.3(12.5)$ \\
\hline
\end{tabular}

used at each test concentration. For each surfactant, ten concentrations in a geometric series were tested in the concentration range first established in a preliminary test. The percentage immobility at $24 \mathrm{~h}$ was plotted against concentration on logarithmic-probability paper. Normal statistical procedures were then employed to calculate the $\mathrm{IC}_{50}$ and to determine the $95 \%$ confidence ranges for the calculated $\mathrm{IC}_{50}$ values.

\section{Results and discussion}

\section{Preparation of monoglyceride arginine surfactants}

The preparation of these surfactants was carried out following a modification of the method used for the synthesis of diglyceride surfactants from arginine. ${ }^{8}$ The synthesis consists of three steps (Fig. 2).

Step 1 is the preparation of $1-O-(N-\mathrm{Cbz}-\mathrm{L}-\operatorname{arginyl})-r a c$-glycerol monochloride (00RZ) by chemical esterification of the $\alpha$ carboxyl group of $\mathrm{N}$-Cbz-L-arginine $\cdot \mathrm{HCl}$ with the primary hydroxyl function of glycerol using boron trifluoroetherate as catalyst. The overall reaction yield was $95 \%$. After purification, the structural product characterisation was the same as described in ref. 8.

Step 2 consists in the synthesis of the 1-acyl-3-O- $(N-\mathrm{Cbz}-\mathrm{L}-$ arginyl)-rac-glycerol $\cdot \mathrm{HCl}(\mathrm{X} 0 \mathrm{RZ})$ by acylation of one hydroxyl group of $00 \mathrm{RZ}$ with the corresponding long chain acid chloride. Usually the acylation of the free hydroxyl group of the $00 \mathrm{RZ}$ compound to obtain diglycerides from arginine is carried out using pyridine as solvent. ${ }^{8}$ Owing to environmental concerns, pyridine is not a recommended solvent for most applications and uses; for this reason, we studied the acylation reaction of the free $\mathrm{OH}$ group of the $00 \mathrm{RZ}$ compound using environmentally friendly solvents and we compared the results with those obtained using pyridine. The most commonly used environmentally friendly solvents in organic reactions are alcohols, which obviously are not appropriate for the acylation reaction. Acetonitrile was used as an alternative solvent; in this solvent the $00 \mathrm{RZ}$ and the acid chloride are soluble. A 1:2 (00RZ-acid chloride) ratio was used to avoid an excess of the diacylated product. ${ }^{8}$ After reaction the mono- and di-acyl compounds were identified and quantified by HPLC analysis.
Table 3 shows the results with pyridine or acetonitrile as a solvent. Using acetonitrile, sodium bicarbonate as base and molecular sieves to remove the water from the medium, a $92 \%$ conversion of the starting reagent was obtained. The HPLC analysis of the reaction mixture showed $58 \%$ of the monoacyl derivative and $33 \%$ of the diacyl derivative.

The isolation of pure monoacyl and diacyl derivatives was carried out by silica gel chromatography. Satisfactory elemental analyses were obtained for these materials, and the FAB-MS and NMR spectra were consistent with the target compounds.

The last synthetic step to obtain the target compounds X0R consists in a catalytic hydrogenation of the $\mathrm{Cbz}$ group using $\mathrm{Pd}$ over charcoal. The reaction was carried out controlling the $\mathrm{pH}$ to prevent the hydrolysis of the ester linkages present in these compounds. Pure compounds were obtained after several crystallisations in methanol-acetonitrile.

The chemical structure of these compounds was checked by NMR. The spectral region around $\delta 3.5-4.8 \mathrm{ppm}$ in the ${ }^{1} \mathrm{H}$ NMR spectra is fairly complex and overlapped because it contains the split resonance signals of the $\mathrm{CH}_{2}$ and $\mathrm{CH}$ groups of the glycerol backbone and those of the $\mathrm{CH}$ of the arginine. Therefore, it was not possible to identify all proton resonance chemical shifts from the ${ }^{1} \mathrm{H}$ NMR spectra. The complete assignment of the carbon resonance signals (Table 2) was achieved by recording the distortionless enhancement by polarisation transfer (DEPT) spectra in which methylene carbon signals appear in the negative phase and methine and methyl ones in the positive phase (Fig. 3).

Once the carbon resonance chemical shifts are known, the $\delta$ 3.5-4.8 ppm region in the ${ }^{1} \mathrm{H}$ NMR spectra was resolved by the 2D PFG HSQC spectrum. This 2D NMR methodology has been extensively used to determine which hydrogens are connected to which carbons through a ${ }^{1} J\left({ }^{1} \mathrm{H}_{-}-{ }^{13} \mathrm{C}\right)$ coupling pathway. The expanded PFG HSQC NMR spectrum of the $\delta$ 3.5-5.6 ppm region recorded in $\mathrm{CD}_{3} \mathrm{OD}$ (Fig. 4) shows cross peaks at $\delta 68.0 / 4.25,68.2 / 4.10,65.73 / 4.18$ and 53.7/4.15. These cross peaks provide the chemical shifts of the overlapped proton resonances in the ${ }^{1} \mathrm{H}$ NMR spectrum. From this experiment the complete assignment of all the carbon and proton resonances was possible. The chemical shifts of both nuclei confirm unequivocally the expected structures.

Table 2 Spectral assignments for the 1-acyl-3-O-(L-arginyl)-rac-glycerol (X0R) compounds

\begin{tabular}{|c|c|c|c|}
\hline Compound & $\mathrm{M}^{+} m / z$ & ${ }^{1} \mathrm{H} \mathrm{NMR}\left(\mathrm{CD}_{3} \mathrm{OD}\right) \delta^{a}$ & ${ }^{13} \mathrm{C} \mathrm{NMR}\left(\mathrm{CD}_{3} \mathrm{OD}\right) \delta^{a}$ \\
\hline $100 \mathrm{R}$ & 403.3 & $\begin{array}{l}0.91\left[\mathrm{t}, 3 \mathrm{H},\left(\mathrm{CH}_{3} \text { of the alkyl chain }\right)\right] \\
\left.1.31\left[\mathrm{~s}, 20 \mathrm{H}, 10 \mathrm{CH}_{2} \text { of the alkyl chain }\right)\right] ; 1.67[\mathrm{~m}, 2 \mathrm{H},(9)]\end{array}$ & $\begin{array}{l}14.46\left[\mathrm{CH}_{3}^{-}, \text {alkyl chain }\right] ; 23.76-41.74 \\
{\left[-\mathrm{CH}_{2}-\text { alkyl chain and }(9),(10)\right]}\end{array}$ \\
\hline $120 \mathrm{R}$ & 431.3 & $\begin{array}{l}1.8\left[\mathrm{~m}, 2 \mathrm{H}\left(\mathrm{CH}_{2}-\mathrm{CH}_{2}-\mathrm{COO}-\right)\right] ; 2.1[\mathrm{~m}, 2 \mathrm{H}(9)] \\
2.4\left[\mathrm{~m}, 2 \mathrm{H}\left(-\mathrm{CH}_{2}-\mathrm{COO}-\right)\right]\end{array}$ & $\begin{array}{l}53.69[(5)] ; 65.73[(1)] ; 68.0[(3)] ; 68.20[(2)] ; \\
158.67[(12)] ; 170.10[(4)] ; 175.26[(21)]\end{array}$ \\
\hline $140 \mathrm{R}$ & 459.3 & $\begin{array}{l}3.4[\mathrm{t}, 2 \mathrm{H},(10)] ; 4.1[\mathrm{~m}, 1 \mathrm{H},(2)] ; 4.15[\mathrm{~m}, 1 \mathrm{H},(5)] ; \\
4,18[\mathrm{~m}, 2 \mathrm{H},(1)] ; 4.25[\mathrm{~m}, 2 \mathrm{H},(3)]\end{array}$ & - \\
\hline Regioisomer & - & $3.6[\mathrm{~m}, 2 \mathrm{H},(3)]$ & - \\
\hline $14 \mathrm{R} 0^{b}$ & - & $4.2[\mathrm{~m}, 2 \mathrm{H},(1)] 5.2[\mathrm{~m}, 1 \mathrm{H},(2)]$ & $63.1(1) ; 76.2(2) ; 61.2(3)$ \\
\hline Regioisomer & - & $3.6[\mathrm{~m}, 2 \mathrm{H},(3)]$ & - \\
\hline $\mathrm{R} 140^{b}$ & - & $5.1[\mathrm{~m}, 1 \mathrm{H},(2)]$ & $61.2(3) ; 72.9(2)$ \\
\hline
\end{tabular}

${ }^{a}$ Assignments corresponding to Fig. 2. The ${ }^{1} \mathrm{H}$ NMR and ${ }^{13} \mathrm{C}$ NMR are that corresponding to $140 \mathrm{R}$. Similar NMR spectra were obtained for the other surfactants. ${ }^{b}$ The ${ }^{1} \mathrm{H}$ NMR and ${ }^{13} \mathrm{C}$ NMR correspond to that of $14 \mathrm{R} 0$ and $\mathrm{R} 140$; the assignments correspond to Fig 5. The table only shows the resonance signals of the glycerol backbone; the rest of signals are similar to those of the $140 \mathrm{R}$ compound. 
Table 3 Formation of X0R compounds (1:2 molar ratio of $00 \mathrm{RZ}$ to acid chloride)

\begin{tabular}{lllll}
\hline & & $\%$ & $\%$ & $\%$ \\
Solvent & Base & Conversion & X0RZ & XXRZ \\
\hline Pyridine & None & 100 & 65 & 35 \\
Acetonitrile & Sodium bicarbonate & 60 & 30 & 30 \\
Acetonitrile with & Sodium bicarbonate & 92 & 58 & 33 \\
molecular sieves & & & & \\
\hline
\end{tabular}

It has been reported for monoglycerides that acyl migration takes place, yielding a balanced mixture of the two regioisomers: 2 -monoglyceride $(10 \%)$ and 1 -monoglyceride $(90 \%) .{ }^{13}$ The DEPT spectra of the synthesised compounds (Fig. 3) show two small carbon resonance signals at $\delta 76.2$ and $72.9 \mathrm{ppm}$ corresponding to two $\mathrm{CH}$ groups. Two carbon resonances from $\mathrm{CH}_{2}$ also appear in the DEPT at $\delta 61.20$ and 63.18 $\mathrm{ppm}$. The chemical shifts of these resonances suggest the presence of the two possible regioisomers of the target compound, XR0 and RX0 (Fig. 5). The cross peaks at 76.2/5.2 and $72.9 / 5.1$ in the PFG HSQC experiment could be due to the $\mathrm{CH}$ (2) of the glycerol backbone in the XR0 and RX0 regioisomers, respectively. Moreover, the cross peaks at 61.9/3.6 could correspond to the $\mathrm{CH}_{2}(3)$ in these regioisomers and the peaks at 63.6/4.24 to the $\mathrm{CH}_{2}(1)$ in the XR0 regiosomer. These assignments are confirmed by the HMBC experiment (Fig. 6). This experiment allows us to determine which hydrogens are connected to which carbons through a ${ }^{2} J\left({ }^{1} \mathrm{H}-{ }^{13} \mathrm{C}\right)$ or ${ }^{3} \mathrm{~J}\left({ }^{1} \mathrm{H}-{ }^{13} \mathrm{C}\right)$ coupling pathway, typically in the range of $1-20$ Hz. The cross peaks at $\delta 76.2 / 3.68$ and $76.2 / 4.16$ show that this $\mathrm{CH}$ group is linked to two $\mathrm{CH}_{2}$ groups $(61.9 / 3.6$ and $63.6 / 4.16$ in the HSQC) and those at 72.9/3.68 and 72.9/4.22 also indicate that this $\mathrm{CH}$ group is linked to two $\mathrm{CH}_{2}$ groups (one being 61.9/3.6 in the HSQC). Based on these studies we can conclude that the carbon resonance signals of the two minority regio- isomers are: $76.22(2), 61.20$ (3) and 63.1 (1) for the XR0 compound and 72.9 (2) and 61.20 (3) for the RX0 compound. The $\mathrm{CH}(1)$ signal of $\mathrm{RX} 0$ could be overlapped with some other resonance of the target compound. The rest of the resonance signals for XR0 and RX0 have the same chemical shifts as those of the $\mathrm{X} 0 \mathrm{R}$ regioisomer (Table 2)

The relative concentrations of the three regioisomers were obtained directly from the relative resonance intensities in the ${ }^{13} \mathrm{C}$ NMR spectrum. ${ }^{13} \mathrm{C}$ NMR has been used to determine the ratio of mono-, di- and triglycerides in commercial mixtures. ${ }^{14,15}$ For analysis requirements, the ${ }^{13} \mathrm{C}$ NMR spectra were acquired using a sufficiently high concentrations and numbers of transients to obtain acceptable signal-to-noise ratios. We also added chromium(III) acetylacetonate $\left(5 \mathrm{mg} \mathrm{ml}^{-1}\right)$ to the sample to decrease the relaxation time of the carbon atoms and to remove the Nuclear Overhauser effect. It was thus possible to obtain the molar ratio of the three regioisomers in the synthetic compound: $82.5 \%$ of $\mathrm{X} 0 \mathrm{R}, 8.5 \%$ of RX0 and $10 \%$ of XR0.

\section{Physicalchemical behaviour}

To check the behaviour of the synthesised monoglycerides of arginine as surfactants in solution, the concentration at which the surfactant molecules start to form micelles, known as the critical micellar concentration $(\mathrm{cmc})$, was determined. The conductivity of an aqueous solution of these compounds at $25{ }^{\circ} \mathrm{C}$ was measured in a concentration ranging from 10 to $0.05 \mathrm{mM}$. The conductivity of the aqueous solutions rose linearly with increasing concentrations up to break points that correspond to the cmc of these surfactants. For the sake of comparison, the cmc value of a pure commercially available monoglyceride, 1-decylglycerol $(10,0,0)$ was also determined. Because of the non-ionic character of this compound, surface tension $(\gamma)$ measurements were used to determine the $\mathrm{cmc}$. The plot of $\gamma$ at $25{ }^{\circ} \mathrm{C}$ of an aqueous solution of the analogue

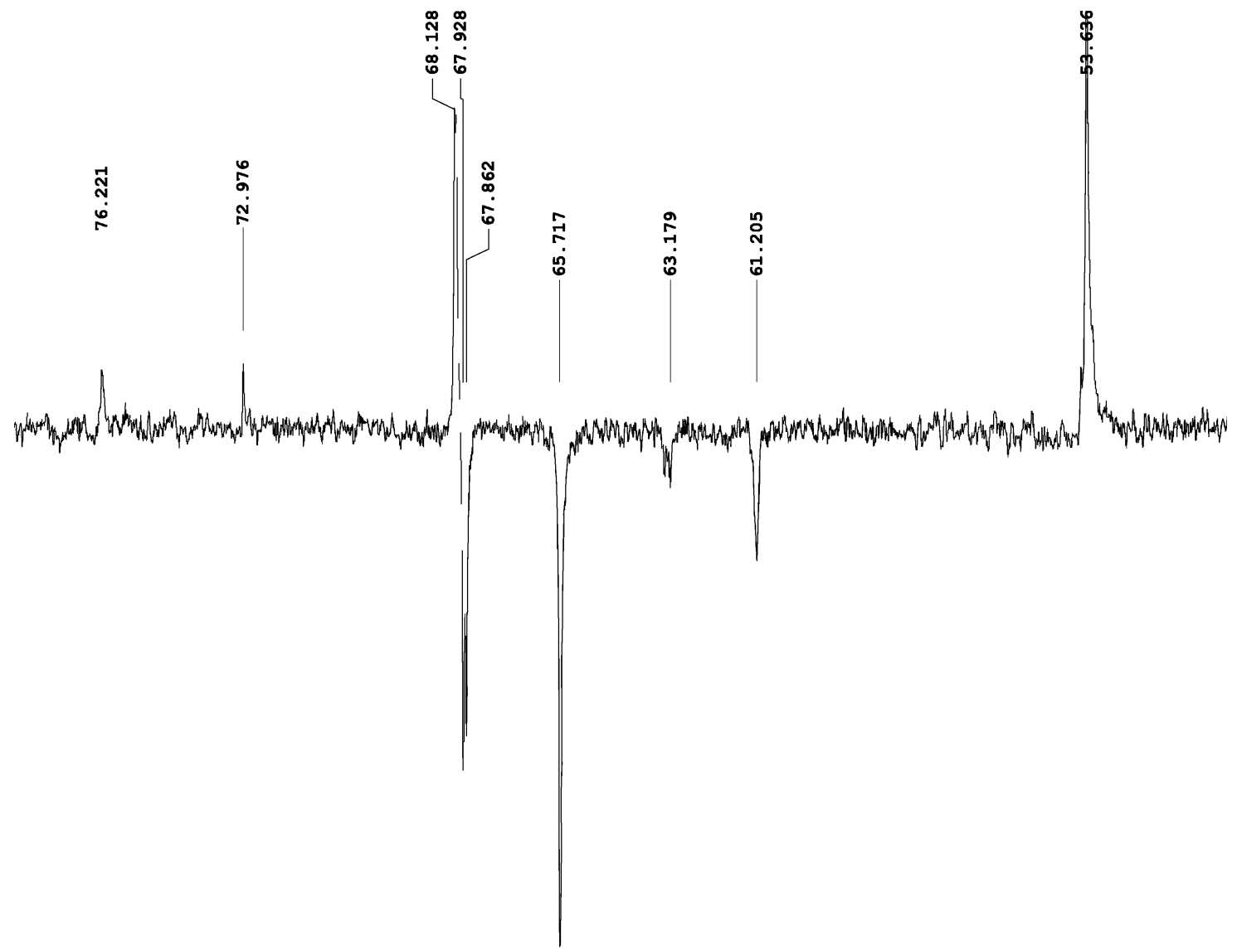

Fig. 3 The expanded DEPT NMR spectrum showing the 52-78 ppm region for 1-miristoyl-3-O-(L-arginyl)-rac-glycerol $\cdot 2 \mathrm{HCl}(140 \mathrm{R})$. 


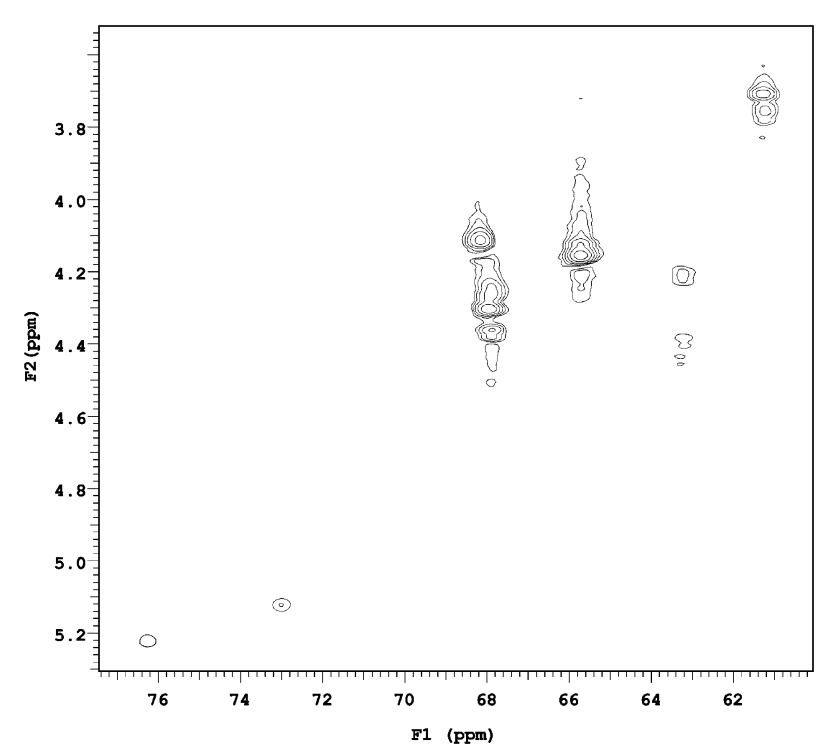

Fig. 4 The expanded 2D gHSQC spectrum of 1-myristoyl-3-O (L-arginyl)-rac-glycerol $\cdot 2 \mathrm{HCl}(140 \mathrm{R})$ showing the $\mathrm{CH}$ and $\mathrm{CH}_{2}$ region of the glycerol backbone.

monoglyceride versus surfactant concentration in water is shown in Fig. 7. The cmc was determined from the break point of the plot.

Micellisation (or cmc value) of the monoglycerides of arginine takes place at $6 \mathrm{mM}$ for $100 \mathrm{R}, 1.3 \mathrm{mM}$ for $120 \mathrm{R}$ and $0.2 \mathrm{mM}$ for $140 \mathrm{R}$. As expected, the cmc decreases when the alkyl chain increases as a consequence of the higher hydrophobic content of the molecule.

Given its non-ionic character, $10,0,0$ shows a cmc value lower than that of the monoglyceride from arginine, 100R, with the same alkyl chain. Comparison of cmc values of monoglycerides from arginine and lysophosphatidylcholine with the same hydrocarbon chain shows that the $\mathrm{cmc}$ values of the X0R compounds are approximately two times higher than those of the lysophosphatidylcholines. ${ }^{16}$ The lysophosphatidylcholine compounds are zwiterionic surfactants and generally appear to have slightly lower cmcs than those of ionic surfactants with the same number of carbon atoms in the hydrophobic group. The cmc values of the new compounds are about one order of magnitude lower than the cmc values of the corresponding 12-carbon straight chain cationic surfactants, which are approximately $1 \times 10^{-2} \mathrm{M} \cdot{ }^{17}$ They also have slightly lower cme than the $N^{\alpha}$-acylarginine surfactants. ${ }^{18}$ The difference between the monoglycerides from arginine and the $N^{\alpha}$-acylarginine type is the glycerol backbone between the arginine and the alkyl chain present in the monoglycerides from arginine.

It has been found that the $\mathrm{cmc}$ is higher when the charge on the ionic group is closer to the $\alpha$-carbon atom of the hydrophobic group. ${ }^{19}$ This is explained as being due to an increase in the electrostatic self-potential of the surfactant ion, when the ionic head group moves from the bulk water to the vicinity of the nonpolar micellar core during the process of micellisation; work is necessary to move an electric charge closer to a medium of lower dielectric constant. ${ }^{19}$ This could account for the low cmc values of the monoglycerides of arginine compared with the $N^{\alpha}$-acylarginine surfactants and the cationic surfactants from quaternary ammoniums (monoQuats). In the monoQuats surfactants, the charge is very close to the $\alpha$ carbon. In the $N^{\alpha}$-acyl arginine surfactants, there are five $\mathrm{CH}_{2}$ groups between the charge and the $\alpha$-carbon, and in the monoglycerides from arginine there are eight $\mathrm{CH}_{2}$ groups between the charge and the $\alpha$-carbon.

On the other hand, compared with the diglyceride surfactants of arginine (1010R and 1212R), the cmc of these compounds is approximately one order of magnitude superior to the $\mathrm{cmc}$ of the corresponding diglycerides, also determined by conductivity. ${ }^{9}$ The second alkyl chain increases the hydrophobic content of the molecule and consequently decreases the cmc values. Nevertheless, the carbon atoms in the second alkyl chain have a much lower effect on the cmc than could be expected. This could be due to the fact that the $\mathrm{cmc}$ obtained by conductivity for the XXR surfactants corresponds to a vesicle-to-ribbon transition and is not a real $\mathrm{cmc}^{20}$ One order of magnitude is also the difference between the $\mathrm{cmc}$ values obtained by conductivity for the monomeric surfactants of arginine, lauroyl (LAM) and caproyl (CAM) arginine methyl esters, and their corresponding gemini surfactants $\mathrm{C}_{n}(\mathrm{LA})_{2}$ and $\mathrm{C}_{n}(\mathrm{CA})_{2}$. In this case, the cmc obtained by conductivity for the gemini surfactants is also a transition between non-globular aggregates and globular micelles. ${ }^{21}$

Based on the cmc values, we calculated the $\Delta G^{\circ}\left(\mathrm{CH}_{2}\right)$ by applying the mass action micellisation model for a monodispersed micelle size: ${ }^{22}$

$$
\Delta G^{\circ}\left(\mathrm{CH}_{2}\right)=R T \log (\mathrm{cmc})
$$

The free energy charge $\Delta G^{\circ}\left(\mathrm{CH}_{2}\right)$ is the energy involved in the transfer of a methylene unit of the hydrophobic group from an aqueous environment to the interior of the micelle. This parameter is negative, thus favouring micellisation, which

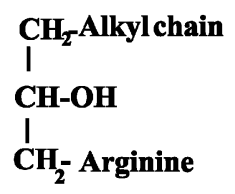

1-acyl-3-O-(L-arginyl)rac-glycerol-2(HCl) XOR

\section{(1) $\mathbf{C H}_{\boldsymbol{2}}$ Alkylchain<smiles>I</smiles> \\ (2)CH-Arginine \\ (3) $\mathrm{CH}_{2}-\mathbf{O H}$}

1-acyl-2-O-(L-arginyl)rac-glycerol-2(HCl) XR0

\section{(1) $\mathrm{CH}_{2}$ Arginine \\ (2) CH-Alkyl chain \\ (3) $\underset{\mathbf{C}}{\mathbf{C}} \mathbf{2}$}

2-acyl-1-O-(L-arginyl)rac-glycerol-2(HCl)

Fig. 5 Regiosomers of the 1-acyl-3-O-(L-arginyl)-rac-glycerol $\cdot 2 \mathrm{HCl}(\mathrm{X} 0 \mathrm{R})$ compounds. 


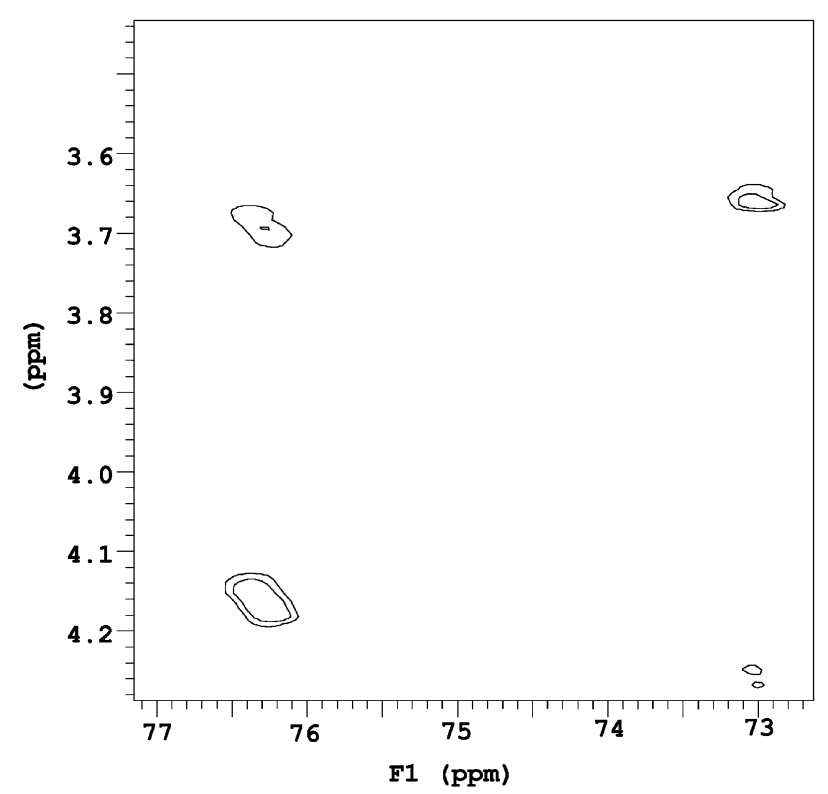

Fig. 6 The expanded 2D gHMBC spectrum of 1-miristoyl-3- $O$ (L-arginyl)-rac-glycerol $\cdot 2 \mathrm{HCl}(140 \mathrm{R})$ showing the $\mathrm{CH}$ and $\mathrm{CH}_{2}$ region of the glycerol backbone.

accounts for the fact that the cmc decreases whereas the length of the hydrophobic group is increased. Fig. 8 shows the variation of $\log (\mathrm{cmc})$ with the surfactant chain length for mono- and diglycerides from arginine. The plots are nearly parallel. These results indicate that the value of $\Delta G^{\circ}\left(\mathrm{CH}_{2}\right)$ is similar for the two families. This behaviour has also been described for gemini surfactants and their corresponding monomeric surfactants, that is for the bis(Args) and LAM ${ }^{2.3}$ and for the bisQuats and monoQuats. ${ }^{24}$

On the other hand, $N^{\alpha}$-acylarginine methyl ester surfactants have lower $\Delta G^{\circ}\left(\mathrm{CH}_{2}\right)$ values than the monoglycerides from arginine. This means that if we introduce a $\mathrm{CH}_{2}$ group into the saturated and straight hydrocarbon chain of the monoglyceride from arginine and the $N^{\alpha}$-acylarginine methyl ester surfactants, a bigger decrease in the cmc values is obtained for the X0R surfactants. Thus, the difference between the cmc values of surfactants from arginine of the same alkyl chain and different polar group, CAM and 100R, LAM and 120R, PAM and 140R, is more significant as the alkyl chain increases.

\section{Antimicrobial activity}

The microbicidal effects of medium- and long-chain fatty acids and their corresponding 1-monoglycerides, of which the most

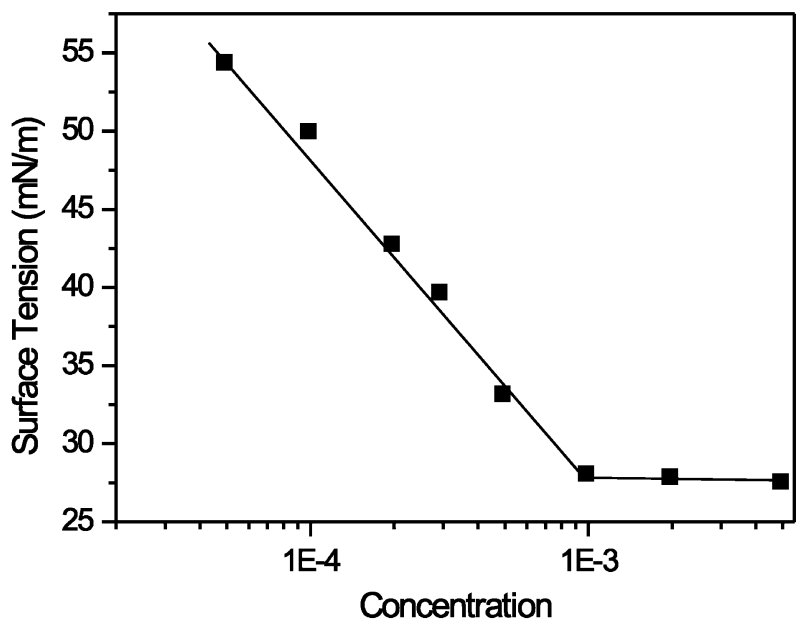

Fig. 7 Surface tension versus $\log C$ for 1-decylglycerol.

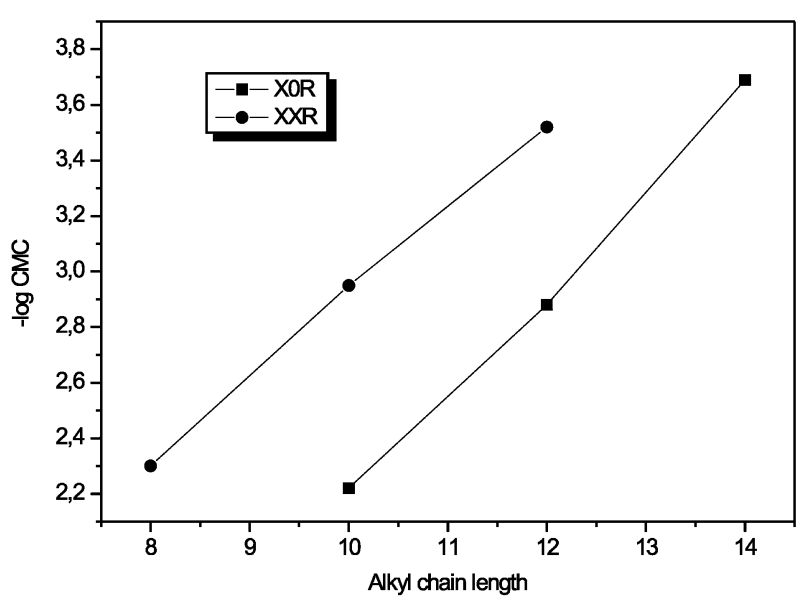

Fig. 8 Relationship between $\log (\mathrm{cmc})$ and the alkyl chain length for the (ם) X0R and the ( $)$ XXR compounds.

active are the compounds with 12 carbon atoms in the alkyl chain, are well-known. ${ }^{25}$ Lauric acid is known to the pharmaceutical industry for its good antimicrobial properties, and the monoglyceride derivative of lauric acid, monolaurin, is known to have even more potent antimicrobial properties against enveloped viruses and numerous pathogenic Gram positive bacteria. $^{26,27}$

In order to study the effect of the introduction of the arginine amino acid in these structures on the antimicrobial properties, these compounds were evaluated for their in vitro antimicrobial activity against Gram positive and Gram negative bacteria. The antibacterial activity of commercial monoglycerides was also determined against the same strains and under the same conditions.

The minimal inhibitory concentration (MIC) values for the synthesised chlorides and for commercial monoglycerides are given in Table 4. Because of the low solubility of commercial monoglycerides in aqueous medium, they were dissolved in the minimum amount of DMF and then diluted with media to the testing concentration. Nutrient broth medium with the same concentration of DMF and without the monoglyceride served as a control in these compounds.

In the light of the results, all monoglycerides from arginine showed antimicrobial activities against a wide range of microorganisms, that is they inhibited the growth of all the microorganisms tested. In all cases the assayed substances showed a moderate activity level against bacteria with MIC values of 64 $256 \mu \mathrm{g} \mathrm{ml}^{-1}$.

Recently we reported the synthesis and antimicrobial properties of diglyceride surfactants from arginine. Fig. 9 shows the percentage $(\%)$ of microorganisms with MIC values lower than $150 \mu \mathrm{M}$ for monoglycerides and diglycerides from arginine. The potency of monoglycerides from arginine does not change drastically with the alkyl chain. As shown in Fig. 9 the capacity of these compounds increased slightly from ten to twelve carbon atoms in the alkyl chain and decreased sharply for palmitate. The optimum biological effect at an alkyl chain length of 12 carbon atoms appears on numerous occasions ${ }^{28-30}$ in antimicrobial surfactants and has been the subject of considerable speculation. This optimum effect can be attributed to the combination of several physicochemical parameters: hydrophobicity, adsorption, cmc and aqueous solubility. A loss of activity occurs for the surfactants with longer alkyl chain lengths because they are less water soluble.

The activity of $88 \mathrm{R}$ and $1010 \mathrm{R}$ (average MIC value of 0.081 $\mathrm{mM}$ ) is considerably superior to the activity of monoglycerides (average MIC value of $0.235 \mathrm{mM}$ ). 88R and 1010R exhibited strong antimicrobial activity similar to the activity of benzalkonium chloride, a well-known biocide compound, and that of 
Table 4 Minimum inhibitory concentration of the X0R compounds and of commercial 1-decylglycerol (10,0,0) and 1-dodecylglycerol (12,0,0)

\begin{tabular}{|c|c|c|c|c|c|c|}
\hline & \multirow[b]{2}{*}{ Microorganism } & \multicolumn{5}{|c|}{$\mathrm{MIC} / \mu \mathrm{g} \mathrm{ml}^{-1}$ and $(\mathrm{mM})$} \\
\hline & & $100 \mathrm{R}$ & $120 \mathrm{R}$ & $140 \mathrm{R}$ & $10,0,0$ & $12,0,0$ \\
\hline \multirow[t]{6}{*}{ Gram positives } & Bacillus cereus var. mycoide ATCC 11778 & $32(0.067)$ & $128(0.254)$ & $128(0.241)$ & $256(1.032)$ & $128(0.463)$ \\
\hline & Bacillus subtillis ATCC 6633 & $128(0.269)$ & $64(0.127)$ & $128(0.241)$ & $128(0.506)$ & $64(0.231)$ \\
\hline & Staphylococcus aereus ATCC 6538 & $128(0.269)$ & $64(0.127)$ & $64(0.120)$ & $256(1.023)$ & $128(0.463)$ \\
\hline & Staphylococcus epidermidis ATCC 12228 & $128(0.269)$ & $128(0.254)$ & $64(0.120)$ & $>$ & $>$ \\
\hline & Micrococcus luteus ATCC 9341 & $128(0.269)$ & $64(0.127)$ & $64(0.120)$ & $>$ & $>$ \\
\hline & Candida albicans ATCC 10231 & $32(0.067)$ & $64(0.127)$ & $128(0.241)$ & $256(1.032)$ & $128(0.463)$ \\
\hline \multirow[t]{11}{*}{ Gram negatives } & Salmonella cholerasuis ATCC 14028 & $32(0.067)$ & $128(0.254)$ & $128(0.241)$ & $256(1.032)$ & $128(0.463)$ \\
\hline & Pseudomonas aeruginosa ATCC 9027 & $256(0.539)$ & $256(0.508)$ & $64(0.120)$ & $256(1.032)$ & $256(0.927)$ \\
\hline & Escherichia coli ATCC 8793 & $128(0.269)$ & $64(0.127)$ & $128(0.241)$ & $64(0.256)$ & $>$ \\
\hline & Arthrobacter oxidans ATCC 8010 & $128(0.269)$ & $64(0.127)$ & $64(0.120)$ & $256(1.032)$ & $64(0.231)$ \\
\hline & Streptoccocus faecalis ATCC 19434 & $128(0.269)$ & $128(0.254)$ & $128(0.241)$ & $256(1.032)$ & $128(0.463)$ \\
\hline & Bortedella bronchiseptica ATCC 4617 & $64(0.134)$ & $64(0.127)$ & $64(0.120)$ & $>$ & $>$ \\
\hline & Citrobacter freundii ATCC 22636 & $256(0.539)$ & $128(0.254)$ & $128(0.241)$ & $>$ & $>$ \\
\hline & Saccharomyces cerevisiae CETT 1383 & $256(0.539)$ & $256(0.508)$ & $128(0.241)$ & - & - \\
\hline & Micobacterium phei 41423 & - & - & - & $>$ & $>$ \\
\hline & Enterobacter aerogenes CECT 689 & $256(0.539)$ & $128(0.254)$ & $128(0.241)$ & $256(1.032)$ & $64(0.231)$ \\
\hline & Klebsiella pneumoniae v. preumonial CIP 104216 & $128(0.269)$ & $64(0.127)$ & $128(0.241)$ & $128(0.516)$ & $>$ \\
\hline
\end{tabular}

new analogues of benzalkonium chlorides. ${ }^{31}$ This demonstrates that the presence of two alkyl chains of 8-10 carbon atoms is effective in improving the intensity of the antimicrobial activity. The interaction with cellular walls is one of the limiting steps in the antimicrobial activity of the compounds. Taking into account that the lipids from the cellular walls form lamellar phases, it is reasonable to suggest that this dimeric structure, which can form lamellar phases, improves the interaction with the wall cells.

The antibacterial activity of monoglycerides from arginine is greater than that shown by commercial pure monoglycerides (Table 4). Half of the negative bacteria tested are resistant to the commercial monoglycerides at the maximum concentration tested whereas the surfactants from arginine are active against all microorganisms tested. The external layer of the outer membrane of some of the Gram negative bacteria is almost entirely composed of lipopolysaccharides and proteins. These bacteria have a hydrophilic surface due to the O side chains of the LPS with the result that hydrophobic molecules such as monoglycerides without any ionic charge may encounter difficulties entering the bilayer.

In the light of these findings, we conclude that the introduction of the basic amino acid arginine in the monoglycerides increases the solubility of these compounds significantly and improves the antimicrobial capability. Currently, resistance to antimicrobial products such as QAC (quaternary ammonium compounds) constitutes a potential problem for the food industry according to a recent report. ${ }^{32}$ These arginine glycerol based surfactants with antimicrobial activity and wide anti-

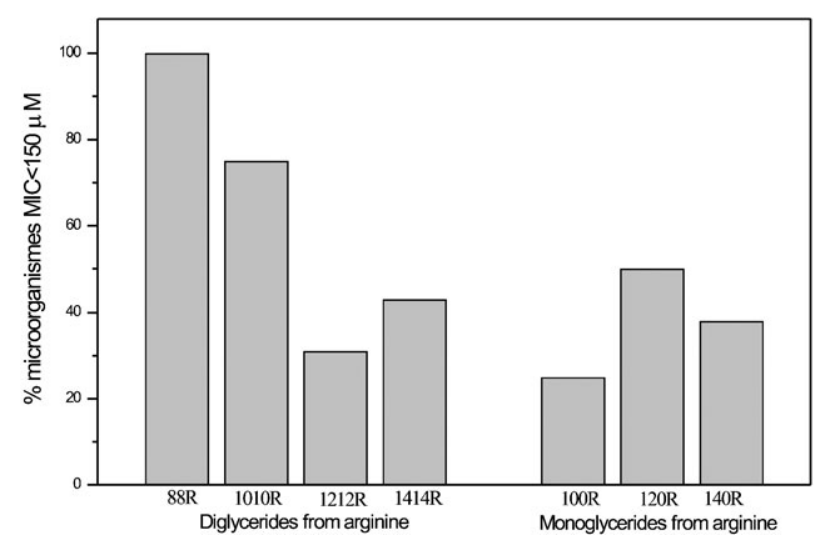

Fig. $9 \%$ Microorganisms inhibited at MIC values lower than $150 \mu \mathrm{M}$ for the mono- and diglycerides from arginine. bacterial spectra could be an interesting alternative. Moreover, the activity shown by these compounds against Escherichia coli and Salmonella is of considerable interest given that these bacteria are common food borne pathogens and pose a serious health hazard owing to increased drug resistance.

\section{Aquatic toxicity assessment}

Biological membranes are essentially non-polar interfaces. Hence, it has been shown that the toxicity of surfactants against aquatic species is caused by the ability of the monomers to disrupt the integrity of the membrane by a hydrophobic/ ionic adsorption phenomenon at the cell membrane-water interface in a way similar to that of the antimicrobial mode of action. The results of Daphnia magna $24 \mathrm{~h}$ immobilisation tests $\left(\mathrm{IC}_{50}\right)$ of the investigated surfactants are given in Table 5. The lower the $\mathrm{IC}_{50}$ value, the higher the toxicity of the compound.

The acute toxicity of the cationic surfactants tested was clearly lower than the toxicity reported for conventional monoquats, ${ }^{33}$ and even lower than that reported for other environmentally friendly cationic surfactant molecules such as arginine based gemini cationic surfactants ${ }^{30}$ and single chain arginine surfactants. ${ }^{28}$ Toxic activity is comparable to that shown by the alkyl arginine methyl esters. ${ }^{30}$

Our data indicate that $100 \mathrm{R}$ exhibits the lowest aquatic toxicity whereas $120 \mathrm{R}$ and $140 \mathrm{R}$ show similar toxic activity. As for the effect of the alkyl chain length, higher toxicity would be expected with greater hydrophobicity of the molecule, as reported for anionic surfactants on Daphnia magna ${ }^{34}$ and for alcohol ethoxylated surfactants on Photobacterium phosphoreum $^{35}$ and on Daphnia magna. ${ }^{36}$ This may explain the increase in toxicity between $100 \mathrm{R}$ and $120 \mathrm{R}$. However, no difference in toxicity between the alkyl chain homologues with 12 and 14 carbon atoms was observed. This could be attributed to the lower bioavailability of the longest alkyl chain homologue owing to its lower solubility. This assumption is enhanced by the results of Daphnia magna for ditallow dimethyl ammonium

Table 5 Acute toxicity of X0R surfactants on Daphnia magna

\begin{tabular}{lll}
\hline \multirow{2}{*}{ Surfactant } & $\mathrm{IC}_{50} / \mathrm{mg} \mathrm{L}^{-1}$ & \\
\cline { 2 - 3 } 100R & Mean value & $95 \%$ Confidence range \\
120R & 82.4 & $70.2-90.3$ \\
$140 \mathrm{R}$ & 18.3 & $14.7-23.9$ \\
\hline
\end{tabular}


chloride (DHTDMAC), which given its lower solubility with respect to the monoalkylquaternary ammonium compounds (QACs) tested, exhibited a lower toxicity. ${ }^{37}$

\section{Acknowledgements}

Financial support from the Spanish CYCIT, ref. PPQ200301834, is gratefully acknowledged.

\section{References}

1 E. Flack, in Butter, Margarine, Spreads, and Baking Fats, Lipid Technologies and Applications, eds. F. D. Gunstone and F. B. Padley, Marcel Dekker, Inc., New York, 1997, pp. 305-329.

2 N. J. Krog, in Food Emulsifiers and their Chemical and Physical Properties: Food Emulsions, eds. S. E. Friberg and K. Larsson, Marcel Dekker, Inc., New York, 3rd edn., 1997, pp. 141-187.

3 M. R. Infante, J. Molinero, P. Erra, R. Julia and J. J. García, Fette Seifen Anstrichmittel, 1983, 87(8), 309-313.

4 S. Pegiadou, L. Pérez and M. R. Infante, J. Surf. Detergents, 2000, 3(4), 517-525.

5 J. Seguer, M. R. Infante, M. Allouch, L. Mansuy, C. Selve and P. Vinardell, New J. Chem., 1994, 18, 765-774.

6 M. Allouch, M. R. Infante, J. Seguer, M. J. Stebe and C. Selve, J. Am. Oil Chem. Soc., 1996, 73(1), 87-96.

7 L. Pérez, J. L. Torres, A. Manresa, C. Solan and M. R. Infante, Langmuir, 1996, 12, 5296-5301.

8 L. Pérez, A. Pinazo, P. Vinardell, P. Clapés, M. Angelet and M. R. Infante, New J. Chem., 2002, 26, 1221-1227.

9 L. Pérez, M. R. Infante, M. Angelet, P. Clapés, A. Pinazo, XVth Conference of the European Colloid and Interface Society, European Colloid and Interface Society, Springer-Verlag GmbH \& Co. KG, Berlin, 2004, , 210-216.

10 R. S. Macober, A Complete Introduction to Modern NMR Spectroscopy, John Wiley \& Sons, New York, 1998, pp. 210-212.

11 J. J. Kotik, P. A. Berger and E. E. Remsen, Macromolecules, 1990 23, 5167-5169.

12 OECD Guidelines for Testing of Chemicals, Method 202: Daphnia sp. Acute Immobilization Test and Reproduction Test, OCDE, Paris, France, 1981.

13 J. Borné, Ph.D. Thesis, Lund University, Lund, Sweden, 2002.

14 R. D. Dawe and J. L. C. Wright, Lipids, 1988, 23(4), 355-358.

15 P. Sacchi, F. Addeo, I. Giudicianni and L. Paolillo, La Rivista Italiane delle Sostanze Grasse, Maggio 1990, LXVII, 245-252.
16 T. Yamanaka, N. Ogihara, T. Ohhori, H. Hayashi and T. Muramatsu, Chem. Phys. Lipids, 1997, 90, 97-107.

17 Milton J. Rosen, Surfactants and Interfacial Phenomena, WileyInterscience Publications, New York, 2nd edn., 1988, pp. 125-127.

18 M. A. Pes, Ph.D. Thesis, Universidad de Barcelona, Barcelona, Spain, 1992

19 Milton J. Rosen, Surfactants and Interfacial Phenomena, WileyInterscience Publication, New York, 2nd edn., 1988, pp. 133-135.

20 R. Pons, L. Pérez and A. Pinazo, Phys. Chem. Chem. Phys., 2004, 6, 1475-1481.

21 A. Pinazo, X. Wen, L. Pérez, M. R. Infante and E. Franses, Langmuir, 1999, 15, 3134-3142.

22 J. H. Clint and T. Walker, J. Chem. Soc., Faraday Trans., 1975, 946-954.

23 L. Pérez, A. Pinazo, M. J. Rosen and M. R. Infante, Langmuir, 1998, 14(9), 2307-2315.

24 R. Zana, M. Berrau and R. Rueff, Langmuir, 1991, 7, 1072-1075.

25 A. J. Conley and J. J. Kabara, Antimicrob. Agents Chemother. 1973, 4(5), 501-506.

26 G. Bergsson, O. Steingrimsson and H. Thormar, Int. J. Antimicrob. Agents, 2002, 20, 258-262.

27 H. Thornar, C. E. Isaacs, H. R. Brown, M. R. Barshatzky and T. Pessolano, Antimicrob. Agents Chemother., 1987, 31, 27-31.

28 C. Morán, P. Clapés, F. Comelles, T. García, L. Pérez, P. Vinardell, M. Mitjans and M. R. Infante, Langmuir, 2001, 17, 5071-5075.

29 F. Devinsky, I. Lacko, F. Bitterova and L. Tomeckova, J. Colloid Interface Sci., 1986, 114(2), 314-319.

30 L. Pérez, M. T. García, I. Ribosa, M. P. Vinardell, A. Manresa and M. R. Infante, Environ. Toxicol. Chem., 2002, 21(6), 1279 1285.

31 J. Pernak, I. Mirska and R. Kmiecik, Eur. J. Med. Chem., 1999, 34, 765-771.

32 E. Heir, G. Sundhelm and A. L. Holck, J. Appl. Bacteriol., 1995, 79, 149-156.

33 M. T. García, I. Ribosa, T. Guindulain, J. Sánchez-Leal and J. Vives, Environ. Pollut., 2001, 111, 169-175.

34 H. A. Painter, The Handbook of Environmental Chemistry. Anthropogenic Compounds. Detergents, eds. N. T. Oude and O. Hutzinger, Springer-Verlag, Berlin, Heidelberg, Germany, 1992, vol. 3, part F, pp. $1-88$.

35 I. Ribosa, M. T. García, J. Sanchez Leal and J. J. Gonzalez, Toxicol. Environ. Chem., 1993, 39, 237-241.

36 D. C. L. Wong, P. B. Dorn and E. Y. Chai, Environ. Toxicol. Chem., 1997, 16, 1970-1976.

37 C. J. Roghair, A. Buijze and H. N. P. Schoon, Chemosphere, 1992, 24, 599-609. 